\title{
CONGELAMENTO DE MADEIRA - AVALIAÇÃO PRELIMINAR DE SUA UTILIZAÇÃO
}

\author{
Rodrigo Giovanella ${ }^{1}$, Graciela Inez Bolzon de Muniz ${ }^{2}$ \\ ${ }^{1}$ Eng. Industrial Madeireiro, M.Sc., Doutorando em Eng. Florestal, UFPR, Curitiba, PR, Brasil - giggio_giovanella@yahoo.com.br \\ ${ }^{2}$ Eng. Florestal, Dr ${ }^{\mathrm{a}}$., Depto. de Engenharia e Tecnologia Florestal, UFPR, Curitiba, PR, Brasil - gbmunize@ufpr.br
}

Recebido para publicação: 29/05/2008 - Aceito para publicação: 18/08/2009

\begin{abstract}
Resumo
O método de congelamento de madeira é conhecido há certo tempo em áreas como conservação e restauro de obras de arte e em algumas etapas de processos industriais, como a secagem de peças de madeira com pequenas dimensões. Entretanto a prática dessa técnica levou, de forma empírica, à percepção de defeitos, estéticos e físicos, em peças tratadas dessa maneira. Portanto, o objetivo deste trabalho foi estudar o efeito do congelamento de peças de madeira e sua influência em processos industriais e procedimentos de conservação e restauro de obras de arte. Os dados obtidos revelaram que as peças submetidas a esse método sofrem uma redução em sua elasticidade, deixando-as com um comportamento mais frágil e plástico. Percebeu-se também que peças com maiores teores de umidade apresentaram um percentual mais acentuado de defeitos, como rachaduras internas e trincas superficiais, e que as estruturas mais afetadas pelo método proposto são as células dos raios. Desse modo, o método de congelamento não é indicado para o tratamento de obras de arte e é aceitável em alguns processos industriais que não exijam um melhor acabamento.

Palavra chave: Congelamento de madeira; rachaduras internas; trincas superficiais; redução de elasticidade.
\end{abstract}

\begin{abstract}
Wooden freezing - Preliminary evaluation of its use. The freezing of wood is a well known method in some study areas, such as conservation and restoration of works of art, as well as in some steps of industrial processes, such as the drying of wood pieces of small size. However, the practice of this technique led, in an empirical way, to the perception of defects (aestethic and phisical) in wood under this treatment. So, the aim of this work was to study the effect of freezing wood pieces and its influence in industrial processes and procedures of conservation and restoration of works of art. The obtained data showed that the wood pieces under this treatment had its elasticity reduced, getting a more fragile and more plastic behavior. It was also noticed that the wood pieces of higher moisture content showed a higher percentual of deffects, such as internal cracks and end checks, and the most affected elements were the ray cells. Thus the method of freezing is not indicated for the treatment of art works and is acceptable in some industrial processes which do not require a better finish. Keywords: Freezing of wood; internal cracks; end checks; elasticity reduction.
\end{abstract}

\section{INTRODUÇÃO}

O método de congelamento de madeira é conhecido, e eventualmente utilizado, há certo tempo em áreas como conservação e restauro de obras de arte, incluindo também documentos em papel, e em algumas etapas do processo industrial, como a secagem de peças de madeira com pequenas dimensões. Hamilton [s/d] comenta que um dos principais problemas apresentados pelo método de congelamento de madeira é a tendência de a superfície desse material ficar axadrezada e desenvolver fissuras, devido à expansão dos cristais de gelo e do consequente dano causado nas paredes das células.

A parede celular dos vegetais é composta basicamente por três elementos, sendo eles a celulose, as polioses e a lignina. A forma e concentração com que esses compostos estão agrupados e distribuídos dependem do tipo do vegetal. Para a madeira, esses elementos estão arranjados de duas formas bem definidas, devido à composição química e orientação dos elementos estruturais (KLOCK et al., 2006). 
Desse modo, podem-se diferenciar duas camadas na parede celular, denominadas de parede primária $\left(\mathrm{P}_{1}\right)$ e parede secundária $\left(\mathrm{P}_{2}\right)$, sendo que $\mathrm{P}_{2}$ apresenta outras três camadas, denominadas de $S_{1}, S_{2}$ e $S_{3}$, conforme mostra a figura 1.

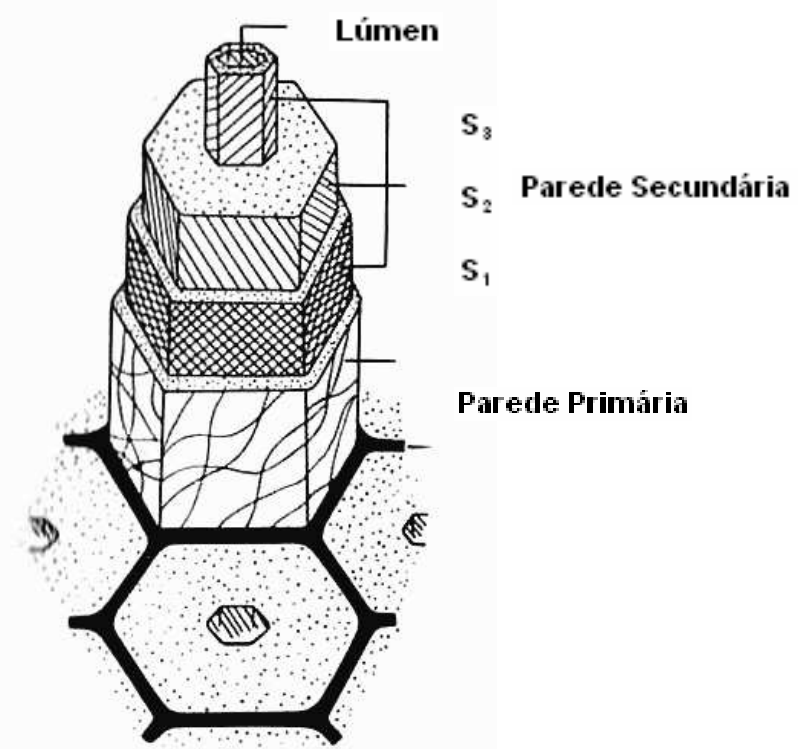

Figura 1 Vista tridimensional de uma fibra vegetal. Figura adaptada de Coutinho (1968).

Figure 1. Three-dimensional sight of a vegetal fiber. Adapted from Coutinho (1968).

Essas camadas são formadas por um conjunto de fibrilas elementares arranjadas de maneira ordenada, conforme figura 2. A maneira com que essas fibrilas elementares se agrupam caracteriza duas regiões distintas, sendo uma cristalina, como resultado de uma forte interação entre as moléculas de celulose, e uma amorfa. É na região amorfa que se encontra a água de impregnação. Segundo Klock et al. (2006), as hidroxilas presentes na estrutura molecular da celulose interagem com a água por meio de ligações de hidrogênio. Essa interação celulose-água e celulose-celulose "baseia-se na interconversão" da ligação de hidrogênio (KLOCK et al., 2006), considerando a quantidade de água presente na madeira. A contração e inchamento sofrido pela madeira são decorrentes da aproximação ou afastamento das fibrilas elementares na região amorfa de sua estrutura celular, o que ocorre devido à presença, ou não, da água nessa região.

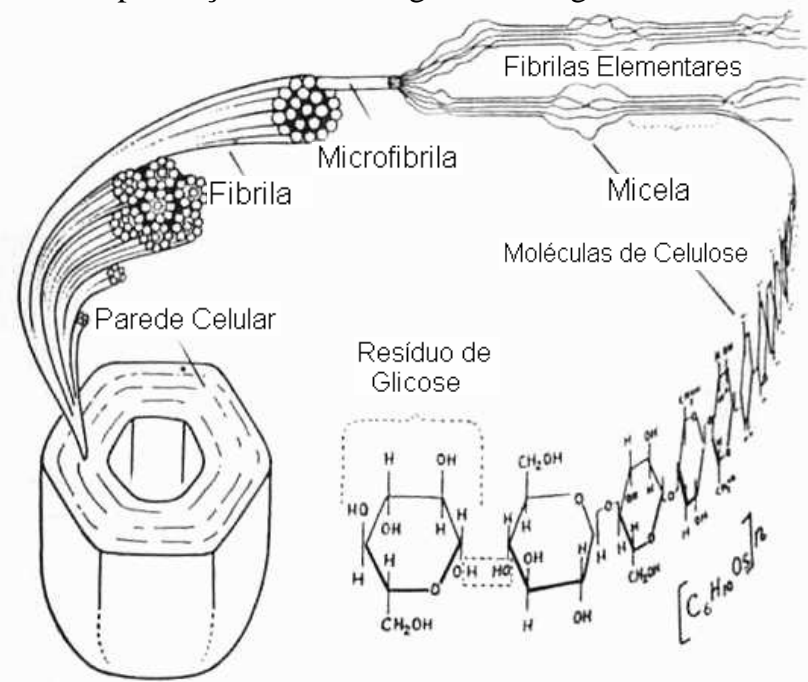

Figura 2. Desenho esquemático dos constituintes da parede celular; emaranhado de fibrilas compostas por um grande número e moléculas filamentosas de celulose. Fonte: Coutinho (1968).

Figure 2. Schematically drawing of the constituent of the cellular wall. Source: Coutinho (1968). 
Desse modo, o comportamento físico da água influencia diretamente o comportamento da estrutura da madeira. Considerando uma expansão da água, devido ao congelamento, e uma contração dos outros elementos (celulose, polioses e lignina), também devido à baixa temperatura, percebe-se uma propensão a colapsos em decorrência do comportamento anômalo da água.

Esse comportamento anômalo é devido às ligações de hidrogênio existentes entre suas moléculas (TAIZ; ZEIGER, 2006), e, para compreender este fenômeno, Ferraz Netto (2007) aponta um estudo sobre a estrutura atômica da água. Segundo esse autor, as moléculas de água interagem entre si de forma ordenada e, devido a sua estrutura, cada molécula só pode realizar quatro ligações. Desse modo, têm-se a formação de uma estrutura tetraédrica, como ilustrado na figura 3.

Podem-se considerar os líquidos como de ordenação limitada, o que significa dizer que existe uma distribuição ordenada ao redor de um átomo (molécula) arbitrariamente escolhido, com certo número de outros átomos (moléculas) em sua proximidade (FERRAZ NETTO, 2007). A partir desse conceito, segundo o mesmo autor, na medida em que cresce a distância com relação à molécula considerada (centro do tetraedro), verificase a alteração gradual dessa ordenação, devido à flexão e rompimento das ligações intermoleculares.
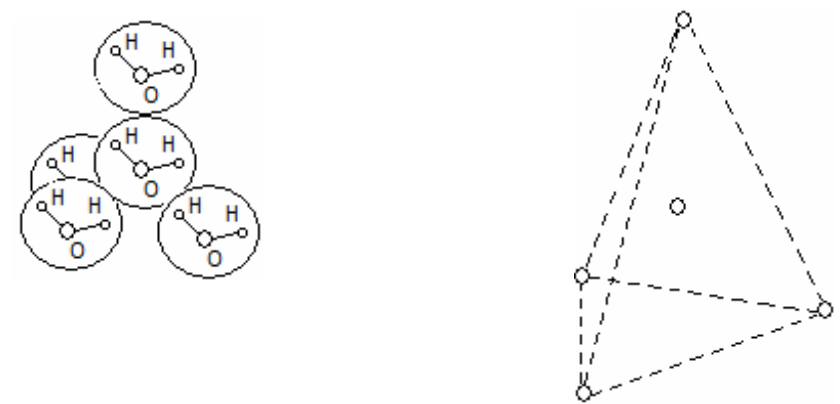

Figura 3. Desenho esquemático da ligação entre as moléculas de água. Fonte: Adaptado de Ferraz Netto (2007).

Figure 3. Schematically drawing of the linking enters water molecules. Adapted from Ferraz Netto (2007).

Com o aumento da temperatura, há um rompimento da estrutura tetraédrica e, como consequência, tem-se um aumento do número de moléculas livres que passam a ocupar os espaços vazios dessa estrutura, que leva a uma diminuição do caráter quasecristalino da água. A estrutura tetraédrica desses aglomerados na água, como substância quasecristalina, e o posterior empacotamento explicam a anomalia das propriedades físicas da água e, em particular, sua anomalia em relação à dilatação térmica (FERRAZ NETTO, 2007).

O objetivo principal deste trabalho é estudar o efeito do congelamento de peças de madeira e sua influência em processos industriais e em procedimentos de conservação e restauro de bens materiais. Tem como objetivos específicos determinar os danos causados pelo processo de congelamento de peças de madeira e analisar a trabalhabilidade da madeira após o congelamento.

\section{Justificativa}

O congelamento de madeira atualmente é um método utilizado em alguns processos industriais, bem como na conservação e restauro de obras de arte. No primeiro caso, as fissuras superficiais e outros danos não aparentes na estrutura do material madeira podem causar complicações nos processamentos subsequentes, seja no âmbito técnico, seja no estético, que inviabilizam o seu uso final com maior valor agregado. No segundo caso, os possíveis danos causados à obra de arte violam o segundo princípio da restauração (BRANDI, 2004) e, desse modo, caracteriza-se como um procedimento impróprio, que pode vir a causar pequenos danos, como rachaduras na camada pictórica (craquelê), aceleramento do processo de desprendimento ou, em escala maior de dano, descaracterização da obra de arte como obra, fazendo-a, assim, perder-se para sempre.

\section{MATERIAIS E MÉTODOS}

\section{Espécies utilizadas}

Foram utilizadas duas espécies, Pinus taeda (Pinaceae) e o Quercus acutissima (Fagácea) (carvalho-japonês). A primeira, representando o grupo das gimnospermas, foi proveniente de plantios 
localizados em Santa Catarina, e a segunda, representando o grupo das dicotiledôneas, foi proveniente de uma área não manejada na região de Curitibanos, Santa Catarina.

\section{Corpos de prova}

Os corpos de prova foram confeccionados a partir de discos retirados de uma árvore de cada espécie. A partir deles, foram obtidos 9 corpos de prova para a espécie de Pinus taeda e 8 para o Quercus acutissima (carvalho-japonês).

No processo de congelamento, as amostras foram divididas, para cada uma das espécies, da seguinte maneira: 3 corpos de prova foram destinados à saturação, 3 para secagem a $0 \%$ e o restante como testemunhas (umidade ambiente e não sendo congeladas).

Os corpos de prova possuíam dimensões iniciais aproximadas de $3,0 \times 2,5 \times 2,5 \mathrm{~cm}$, que foram posteriormente medidas com maior exatidão $( \pm 0,05 \mathrm{~cm})$ com o auxílio de um paquímetro. Outro parâmetro importante mensurado foi o peso dos corpos de prova, que foram medidos em uma balança com precisão de $0,001 \mathrm{~g}$.

\section{Preparação das amostras}

Os corpos de prova foram medidos em massa, comprimento, largura e espessura. Nesse momento, os corpos de prova destinados a serem testemunhas foram isolados do meio para que não houvesse alteração de umidade no decorrer do processo.

Os corpos de prova definidos como saturados, para alcançar essa condição, foram submersos em água até que fosse detectado um valor de massa constante.

Os corpos de prova secos (a $0 \%$ de umidade) passaram por um processo de secagem, sendo colocados em uma câmara a $100^{\circ} \pm 2{ }^{\circ} \mathrm{C}$ até permanecerem com massa constante.

Após a saturação de um grupo e secagem do outro, essas amostras foram isoladas, em sacos plásticos fechados a vácuo, para que não houvesse interação amostra-meio. Feito isso, essas amostras foram medidas novamente nos parâmetros já citados.

\section{Fase de congelamento}

Com os corpos de prova preparados e medidos, passou-se à fase de seu congelamento. As amostras saturadas e as secas foram colocadas em um freezer a uma temperatura de aproximadamente $5{ }^{\circ} \mathrm{C}$ (estimada de forma a não promover um congelamento muito rápido), e as testemunhas permaneceram à temperatura ambiente.

Foram feitas medições de massa por um período de 4 horas, em intervalos de uma hora, e uma medida após 24 horas, o que totalizou cinco medidas de massa para cada corpo de prova.

\section{Análise dos corpos de prova \\ Congelamento}

Para análise dos corpos de prova, foi adotado o procedimento visual macroscópico, com o auxílio de uma lupa e registro fotográfico, e o procedimento visual microscópico, também com o registro dos dados por meio de fotografia digital.

\section{Trabalhabilidade}

Para a análise da trabalhabilidade, foram utilizadas algumas ferramentas manuais (formões, brocas e serras) e observado o comportamento das amostras congeladas, mediante o uso delas (beneficiamento) em comparação às peças não congeladas.

Para a realização dos testes de trabalhabilidade, foi feito um acondicionamento das peças de madeira (congeladas - saturadas/secas - e testemunhas) para que ficassem em umidade de equilíbrio com o meio.

\section{RESULTADOS E DISCUSSÃO}

Como se pode visualizar na tabela 1 , houve uma variação de massa para todas as amostras analisadas, e essas variações foram positivas, significando um aumento relativo de sua massa no decorrer do processo de congelamento. Isso se deve ao comportamento anômalo da água, em que há um aumento 
de densidade em temperaturas entre $0^{\circ}$ e $4^{\circ} \mathrm{C}$. Entretanto as amostras secas, apresentaram uma variação semelhante à das amostras saturadas. Esse fato leva a uma reflexão mais profunda, em que o foco são as ligações de hidrogênio dos resíduos de glicose da região amorfa da madeira e as suas semelhanças, em termos de geometria, com as ligações de hidrogênio da água pura. Ou seja, a madeira, independentemente da água, apresentou um pequeno aumento de densidade quando exposta a condições de baixas temperaturas, isso possivelmente devido ao arranjo eletrônico das ligações de hidrogênio e o posicionamento dos resíduos de glicose na região amorfa.

Tabela 1. Variação de massa ao longo do processo de congelamento. As letras $\mathrm{P}$ e $\mathrm{J}$ representam as espécies Pinus taeda e o Quercus acutissima (carvalho-japonês), respectivamente.

Table 1. Variation of mass throughout the freezing process. Letters $\mathbf{P}$ and $\mathbf{J}$ respectively represent the species Pinus taeda and Quercus acutissima.

\begin{tabular}{lccc}
\hline Amostras saturadas & Variação de massa (\%) & Amostras secas & Variação de massa (\%) \\
\hline P1 & 2,4 & P4 & 2,0 \\
P2 & 2,6 & P5 & 1,9 \\
P3 & 2,4 & P6 & 2,5 \\
J1 & 2,6 & J4 & 3,1 \\
J2 & 3,1 & J5 & 2,9 \\
J3 & 3,1 & J6 & 3,3 \\
\hline
\end{tabular}

As amostras que serviram como testemunhas não apresentaram variação de massa ao longo do processo, o que permite dizer que o aumento de massa observado nas amostras submetidas ao freezer está associado também ao congelamento dos constituintes da madeira, reforçando as afirmações do parágrafo anterior.

De acordo com as observações qualitativas, a densificação observada nas peças de madeira após o congelamento ocorreu devido ao fato de a variação positiva de massa ser superior à variação positiva de volume, resultando numa relação massa/volume superior para o estado congelado, tanto para as amostras saturadas como para as secas. O aumento da densidade da madeira permite dizer que, para o estado de congelamento, os valores do módulo de ruptura (MOR) e módulo de elasticidade (MOE) se alteraram. De maneira simples, um aumento de densidade resulta em um maior valor de resistência, entretanto uma menor elasticidade. Essa redução no MOE significa uma diminuição da região de escoamento (visualizada na relação tensão/deformação de materiais dúcteis), que altera todo o comportamento tecnológico do material (mencionado a seguir) e, como consequência, os parâmetros de controle em seu beneficiamento. Ressalta-se, nesse ponto, a necessidade de um estudo específico para a análise da transição do comportamento da madeira de um material dúctil para frágil, com ênfase na redução da região de escoamento e o aumento proporcional relativo do MOR.

Entretanto, de acordo com as análises quantitativas (análise de variância e teste de Tukey) dos dados obtidos, não se verificou diferença estatística, em um nível de significância de cinco por cento, entre as massas iniciais e finais para ambas as espécies, fato este que pode estar relacionado ao número de amostras utilizado e sua homogeneidade.

Segundo as análises visuais realizadas, percebeu-se que as amostras saturadas, para as duas espécies estudadas, apresentaram extensas rachaduras superficiais, o que não foi verificado nas amostras secas previamente (Figura 4). Como se pode visualizar, as rachaduras e fissuras observadas no carvalhojaponês são maiores do que as observadas no Pinus taeda. Entretanto, Pinus taeda apresentou um número superior de rachaduras, apresentando, desse modo, uma maior área superficial com esse defeito. Outra condição observada é que as rachaduras, para ambas as espécies, ocorreram exclusivamente paralelamente aos raios, sendo estas as estruturas mais afetadas.

Foi observado, principalmente nas amostras saturadas, um pequeno aumento no volume do corpo de prova, fato este que justifica a formação de maiores rachaduras nessas amostras, pois a água presente no interior da madeira aumentou seu volume, graças ao seu comportamento anômalo, enquanto que os outros constituintes sólidos (celulose, poliose e lignina) reduziram o seu volume (cada um individualmente). Ou seja, ao contrário do que se espera para um corpo sólido, a madeira aumentou seu volume graças à água presente em seu interior. Como consequência, houve um aumento da pressão interna em pontos específicos que geraram os defeitos observados. Entretanto deve-se determinar para cada constituinte qual é a relação de contração ou expansão (conforme especulado para celulose) frente a 
baixas temperaturas, para que, no somatório destas, visualize-se o que realmente ocorreu com o sólido madeira (desconsiderando a água em seu interior), possibilitando detectar a origem das tensões de ruptura da madeira congelada. Outro fato percebido para amostras saturadas foi que, no decorrer do congelamento, cristais de gelo foram se formando na superfície do corpo de prova. Isso ocorreu graças à dilatação da água livre presente no lúmen das células próximas à superfície da madeira, fazendo parte dessa água se acumular e cristalizar na referida superfície.

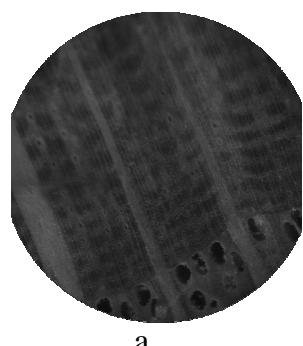

a

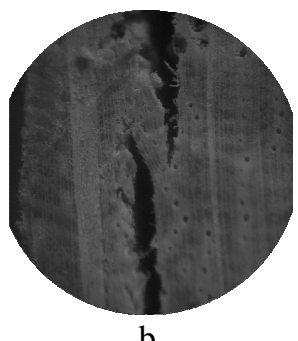

b

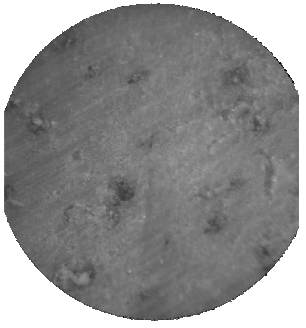

C

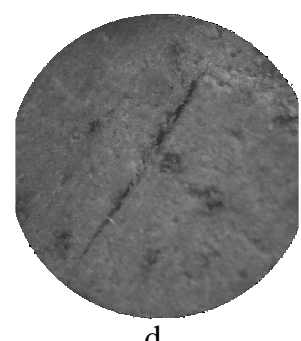

d

Figura 4. Fotos macroscópicas de Quercus acutissima (carvalho-japonês), sendo amostra seca (a) e saturada (b); e Pinus taeda, sendo amostra seca (c) e saturada (d).

Figure 4. Macrocospic photos of Quercus acutissima being dry (a) and saturated (b) sample; and Pinus taeda being dry (c) and saturated (d) sample.

A trabalhabilidade das peças que passaram pelo processo de congelamento foi afetada de forma a reduzir a elasticidade do material madeira, deixando-o com um comportamento mais frágil e plástico. As peças de madeira congeladas, saturadas e secas, apresentaram um maior índice de arrepiamento das fibras e um maior desprendimento de lascas sob solicitações de corte. Sob o ponto de vista de processos industriais, essa alteração no comportamento do material é negativa, pois este certamente irá apresentar uma maior perda por defeitos gerados durante o processo de beneficiamento. Madeiras com esse comportamento têm maior propensão a rachaduras quando em contato com serras ou outras ferramentas de mesmo propósito. O processo de secagem também deve ser mais cuidadoso, pois a madeira está mais frágil, facilitando desse modo o surgimento de defeitos como rachaduras, trincas internas, colapsos e empenamentos, além do fato de a madeira estar levemente mais permeável, devido aos danos gerados pelos cristais de gelo em sua estrutura macroscópica, fato este que pode afetar diretamente programas de secagem, quando utilizados.

Sob o ponto de vista da restauração (de obras de arte), a alteração da trabalhabilidade da madeira é um fator extremamente delicado. Normalmente, o processo de congelamento de obras de arte é utilizado para desinfestação de peças para posterior restauração. Ou seja, é uma ação corretiva, ou curativa, que antecede as intervenções de restauro. Desse modo, a alteração da trabalhabilidade influencia todos os procedimentos posteriores, principalmente os de intervenção mecânica, isso devido ao fato de a madeira passar a comportar-se de maneira incerta frente a essas intervenções. Deve-se considerar ainda que, devido à mudança no comportamento tecnológico da madeira, ela pode apresentar problemas de acabamento superficial e tratamento químico (como exemplo, tem-se arrepiamentos intensos, que podem inclusive alterar a textura e a permeabilidade do material).

Outro fator relevante para a ciência da restauração é a alteração de MOR e MOE. O fato de se ter um aumento no MOR pode ser benéfico em certas ocasiões, sobretudo quando se tem peças fragilizadas por ataque de agentes xilófagos, por exemplo. Entretanto, a perda no MOE deve ser considerada, pois a peça pode estar em condição de fadiga mecânica e entrar em colapso mesmo com um aumento do MOR e mantendo a mesma carga.

\section{CONCLUSÕES}

De acordo com os resultados obtidos, sob as condições deste experimento, conclui-se que:

- Peças de madeira que passaram pelo processo de congelamento apresentaram um aumento de massa sem significativa alteração de volume, gerando, desse modo, rachaduras internas ao longo de toda a peça e trincas superficiais. 
- Os danos causados pelo processo de congelamento são mais evidentes nas estruturas dos raios, sugerindo que essas estruturas celulares são as mais afetadas.

- Os defeitos observados foram originados a partir do aumento da pressão interna em pontos específicos, onde houve a formação de cristais de água (gelo).

- A trabalhabilidade do material madeira foi afetada de maneira a reduzir a sua elasticidade, fazendo com isso os processos subsequentes de beneficiamento ficarem prejudicados (maiores perdas).

- Peças de madeira que passaram pelo processo de beneficiamento após o congelamento apresentaram maior índice de arrepiamento ao corte e maior desprendimento de lascas quando sujeitos à perfuração.

- Devido à alteração da trabalhabilidade, os processos de intervenção mecânica em obras de arte de madeira exigem um maior cuidado, devido à fragilidade adquirida pelo material.

- O método de congelamento é contraindicado a qualquer processo de conservação e/ou restauro de obras de arte constituídas com o material madeira. Da mesma forma, o método é contraindicado para processos industriais cujos fins das peças exijam uma qualidade superior de acabamento.

\section{REFERÊNCIAS}

BRANDI, C. Teoria da restauração. Cotia, São Paulo: Ateliê Editorial, 2004, 2. ed., 261 p.

COUTINHO, L. M. Curso de Ciências Biológicas - Botânica. São Paulo, Editora Cultrix, v. 2. 1968. $307 \mathrm{p}$.

CUNHA, C. R. A atualidade do pensamento de Cesare Brandi. Resenha do livro "Teoria da Restauração", de Cesare Brandi. Atividade de pesquisa complementar de mestrado, USP, 2007.

FERRAZ NETTO, L. Comportamento anômalo da água. In: www.feiradeciencias.com.br. Acessado em 06/08/2007.

FRONER, Y. A. Estudo referente à conservação de objetos de museus. In: Recriando o Museu (apostila de curso), Secretaria da Cultura do Estado do Paraná, 2005.

GALVÃO, A. P. M.; JANKOWSKY, I. P. Secagem racional da madeira. São Paulo, Editora Nobel, 1988. $111 \mathrm{p}$.

GIOVANELLA, R. Conservação e restauro de obras de arte que utilizam a madeira: métodos de preservação e controle da degradação. In: $13^{\circ}$ EVINCI - Evento de Iniciação Científica. Imprensa Universitária da UFPR, Livro de Resumos, vol. único, 2005, Curitiba.

HAMILTON, D. L. Secagem por congelamento. In: Conservação de achados submarinos: conservação da madeira. Apostila de Curso. s/d. 15 p.

KOLLMANN, F. P.; CÔTÉ, W. A. Principles of wood science and technology. Impresso na Alemanha, Editora Springer-Verlag, Heidelberg, vol. I, 1968. 592 p.

KLOCK, U.; MUNIZ, G. I. B.; HERNANDEZ, J. A. Química da madeira. Série didática, FUPEF, 3. edição, 2006. 86 p.

TAIZ, L.; ZEIGER, E. Fisiologia vegetal. São Paulo, Artmed, 3. ed., traduzida, 2006. 719 p. 
FLORESTA, Curitiba, PR, v. 40, n. 2, p. 311-318, abr./jun. 2010. Giovanella, R.; Muniz, G. I. B. de 